\title{
Labirintos conceituais científicos, nativos e mercadológicos: pornografia com pessoas que transitam entre os gêneros*
}

Jorge Leite Jr."*

\begin{abstract}
Resumo
O objetivo deste artigo é discutir como a pornografia, em especial a pornografia envolvendo pessoas que transitam entre os sexos/ gêneros, lida com uma das questões mais características das ciências sociais: a tensão entre as categorias científicas, concepções nativas e classificações mercadológicas. No cada vez mais saturado e competitivo mercado mundializado da pornografia, a difusa fronteira entre a universalidade científica e a regionalidade nativa mostra-se como um vasto território a ser colonizado pela lógica da indústria pornô.
\end{abstract}

Palavras-chave: Pornografia, Travestis, Transexuais, Exotismo, Categorias.

" Recebido para publicação em 12 de outubro de 2011, aceito em 12 de novembro de 2011.

** Professor do Departamento de Sociologia da Universidade Federal de São Carlos - UFSCar. jcabelo@uol.com.br

cadernos pagu (38), janeiro-junho de 2012:99-128. 
Labirintos conceituais científicos, nativos e mercadológicos

Scientific Categories, Native Conceptions and Marketable Classifications: Pornography and Conceptual Labyrinths

\begin{abstract}
This paper aims to discuss how pornography, especially that which involves people who move between sexes/genders, deal with one of the most characteristic issues of social science: the tension among scientific categories, native conceptions and marketable classifications. In the (even more) saturated and competitive worldwide pornography market, these diffuse boundaries are presented as a vast territory to be colonized by the porn industry logic.
\end{abstract}

Key Words: Pornography, Travesties, Transsexuals, Exoticism, Categories. 
Jorge Leite Jr.

A pornografia não é um tipo de obra cultural específica, mas, antes de tudo, uma forma de ordenação conceitual. A classificação "pornografia" é uma maneira de organizar e selecionar produções culturais, no caso, relacionadas às representações da sexualidade. Sendo assim, ela é indissociável das ideias e do momento histórico que a conformaram e que ainda hoje a organizam.

Neste artigo, chamarei de pornografia ${ }^{1}$ todo tipo de produção escrita, musical, plástica ou audiovisual que seja voltada para um mercado próprio e que tenha como principal objetivo a obtenção do lucro econômico através da excitação de seu público consumidor. Não farei então distinção entre as imagens ditas explícitas ou implícitas, indiretas ou diretas, transgressivas ou conformistas. Da mesma forma, também não farei distinção entre "pomografia" e "arte erótica", pois, conforme Pierre Bourdieu (1988), a tentativa de distinguir esses dois campos demonstra o esforço para legitimar certas expressões sócio-culturais em detrimento de outras, seguindo a lógica da hierarquização das diferenças dessas mesmas expressões, visando a conquista, manutenção ou perda de capital cultural e social. O que importa para esta análise é a representação da sexualidade como um negócio, seja ele do ramo elitizado e culturalmente valorizado (arte erótica) ou do ramo popular e midiatizado, comumente considerado inferior e/ou vulgar (pornografia). Vejamos então como essa forma de classificação, a pornografia, foi criada historicamente.

No início do século XIX, arqueólogos italianos descobrem, entre as ruínas de Pompéia, uma série de objetos e imagens sexuais até então só vistas de maneira tão "explícita" em obras consideradas obscenas e impróprias para circularem livremente pela sociedade. O Museu de Nápolis resolve mantê-las em área reservada, proibindo a visitação de mulheres, crianças e homens incultos (Freire, 2001:66). Para nomear tais obras, em 1819, o diretor do museu utilizou a expressão "gabinete de objetos

1 É importante esclarecer que trabalharei neste artigo apenas com a pornografia legalizada. 
obscenos". Em 1823, esse nome é alterado para "gabinete de objetos reservados" e, em 1860, sob a direção do escritor francês Alexandre Dumas (pai), o conjunto passa a ser chamado de "coleção pornográfica", expressão originada do termo "pornografia", significando "escritos sobre prostitutas" (Grant e Mulas, 1976:168).

Inventam-se então duas palavras novas ${ }^{2}$ (pornográfica $e$ pornografia), originadas do grego, como uma barreira linguística ao acesso de tal produção, afastando assim tanto a evocação explícita do termo "obsceno" (Moraes, 2003), quanto o estímulo à curiosidade associado à palavra "secreto". Ora, o importante no surgimento desse novo vocábulo é que, conforme Bourdieu, nomear é criar. Assim, não é um conglomerado de imagens ou objetos que está sendo criado, mas um tópico conceitual para, a partir de um novo ponto de vista, conhecer, reconhecer e situar cultural e socialmente tais obras de acordo com valores já consagrados por quem nomeia: a língua não é somente um instrumento de comunicação ou mesmo de conhecimento, mas um instrumento de poder (Bourdieu, 1983:160).

Não por acaso, é nesse mesmo período, a segunda metade do século XIX, que surge a produção literária e visual reconhecida hoje em dia também como pornografia: a representação da sexualidade e a produção de objetos para uso sexual como um negócio que visa em primeiro lugar o lucro econômico e possui um mercado específico. Com o incremento das gráficas e editoras e um aumento substantivo de consumidores e leitores, surge então a "pornografia" como classe independente de obras literárias, pictóricas e produtos distintos, especialmente na Europa Ocidental, logo alcançando as Américas, em especial os Estados Unidos. "Em outras palavras, a pornografia como categoria regulamentada surgiu em resposta à ameaça de democratização da cultura" (Hunt, Lynn, 1999:13). Rapidamente o termo se dissemina, e essa palavra cada vez mais passa a fazer parte da

2 Embora o termo "pornógrafo" tenha sido criado em 1796 pelo escritor francês Restif de La Bretonne. 
Jorge Leite Jr.

linguagem cotidiana. Assim, apesar de ter surgido no meio acadêmico (em um museu arqueológico), a palavra "pornografia" parece ter logo se descolado de sua origem, adquirindo vida própria em outras searas.

Dentro de todas as mudanças sociais e epistemológicas que ocorrem nesse momento, não apenas a ciência vai criar categorias e conceitos para discursar e debater sobre os sexos, gêneros, desejos e práticas sexuais, mas também a nascente cultura de massas. Dessa forma, o termo "pornografia" não se desenvolve como uma categoria científica - portadora de um rigor conceitual e de uma definição clara - mas consolida-se como uma ideia imprecisa, difundida no senso comum e alimentada pela indústria do entretenimento. Minha argumentação é de que a pornografia, sendo uma concepção difusa, ora histórica, ora valorativa e ora comercial, sem nunca ser inteiramente uma ou totalmente outra, sustenta-se através dessa imprecisão conceitual. E justamente por conta dessa fluidez, o próprio mercado pornô (ou aquilo que é considerado como) cria suas centenas de subclassificações, além de usar categorias consagradas em outras áreas (como a ciência e as culturais locais) que, por sua vez, ajudam a alimentar esta incerteza classificatória.

Sendo um discurso sobre sexo sob a lógica da espetacularização, a pornografia visa atingir, antes de tudo, não a constância da razão abstrata, mas a fugacidade das reações físicas, sendo um tipo específico de produto mal-afamado por ser considerado "sensacionalista", ou seja, que visa estimular as sensações corporais (El Far, 2004). A pormografia nasce como uma forma de classificação socialmente reconhecida, mas cientificamente indefinida, sob o viés da cultura de massas e do entretenimento.

Provavelmente por isso, rapidamente a "pornografia" também se desenvolve como um termo possuidor de determinado sentido valorativo, comumente de caráter desqualificante $e$ pejorativo, pois ela passa a ser vista como possuindo uma "intenção deliberada de violar tabus morais e sociais" (Gregori, 2004:236). Assim, essa palavra passa a ser usada em vários tipos 
de discurso (do médico ao sociológico), principalmente para nomear determinadas representações da sexualidade que vão contra os valores de quem classifica essas obras, especialmente no campo estético e/ou moral. "Pornografia" passa então a representar aquilo que é desqualificado socialmente, visto ora como vulgar, ora como perigoso, mas constantemente compreendido como algo não legítimo e passível de repressão, seja legal ou simbólica.

Novamente com Bourdieu (1988), podemos afirmar que a classificação também é uma maneira de classificar o classificador. Dessa forma, classificar determinadas obras como pornografia diz muito menos sobre as obras em si do que sobre os valores de quem faz esse julgamento. As produções chamadas de pornográficas são então comumente consideradas como aquilo que transforma o sexo em produto de consumo, estando ligadas etimologicamente ao mundo da prostituição e visando a excitação "desregrada" dos sentidos e apetites sexuais, sendo essas características (reais ou não) vistas como degradantes e/ou nocivas.

É nesse sentido que obras dos mais variados períodos históricos, da Antiguidade ao início do século XXI, passando pela Idade Média, Renascimento e Iluminismo, e mesmo produções de outras culturas serão classificadas como "pornográficas", tais como os livros do Marquês de Sade ou desenhos japoneses do século XVI. Dentro dessa concepção valorativa, aquilo que não é considerado uma expressão legítima da sexualidade, ou seja, aquilo que choca ou contraria os valores - afetivos, religiosos, filosóficos e, principalmente, estéticos - de quem faz tal julgamento, é enquadrado dentro da classificação minorizante de pornografia. Essa concepção, utilizada para classificar representações da sexualidade vistas como inferiores e perigosas socialmente, vai se manter atuante até os dias do hoje.

Mas pode-se afirmar que, atualmente, "pornografia" não é apenas um termo valorativo ou um tipo específico de representação da sexualidade datado historicamente, mas também uma classificação mercadológica. Conforme visto, a pornografia, 
Jorge Leite Jr.

como um negócio em si, surge apenas no fim do século XIX, tendo como objetivo primeiro a obtenção de lucro. A divulgação de ideias, vistas como progressistas ou conservadoras, está submetida a essa lógica. Inicialmente como um negócio clandestino, sua história durante o século $\mathrm{XX}$ é a história da criação e da legalização de seu mercado. E mesmo não sendo mais proibida na grande maioria dos países ocidentais a partir da década de 70 do século XX - dentro de um processo gradual e repleto de conflitos filosóficos, religiosos e legais -, a pornografia ainda é encarada como ilegítima culturalmente (caráter valorativo.

Ainda assim, a palavra "pornografia" não é algo preciso, nem no campo valorativo, nem no mercadológico. Isso fica claro quando fazemos a simples pergunta: quanto rende a pornografia? Para essa questão ser respondida com o mínimo de confiabilidade, deve-se esclarecer antes de tudo o que se entende por pornografia e quais os produtos serão contabilizados nessa classificação. Filmes, revistas, livros, músicas, esculturas, objetos utilitários, roupas, programas de TV (aberta, a cabo ou pay-perview), empresas de disk-sexo, sítios da internet, salas de batepapo, tudo isso é levado em conta quando se pretende falar pelo mercado pornô? Ou apenas alguns desses produtos?

Por exemplo, quando se fala de livros, contam-se obras como A filosofia na Alcova, do Marquês de Sade, $O$ amante de Lady Chatterley, de $\mathrm{D}$. $\mathrm{H}$. Lawrence, $\mathrm{O}$ doce veneno do escorpião, de Bruna Surfistinha (Raquel Paxeco), o Kama Sutra, de Vatsyayana, O jardim das delícias, do Xeique Nefizaui, A aliciadora feliz, de Xaviera Hollander, The big butt book ou Erotica Universalis, ambos da editora Taschen? Na questão da música, as letras do grupo de funk Gaiola das Popozudas são agrupadas junto como os forrós do cantor Genival Lacerda? O filme $O$ império dos sentidos (dir: Nagisa Oshima, Japão-França, 1976) pertence a essa categoria tanto quanto Elas gostam atrás 2 (produtora Brasileirinhas, Brasil, 2008)? Os dildos, vibradores e baralhos com posições sexuais e demais produtos vendidos em sex shops (conforme analisado por Gregori, 2004) são 
contabilizados? Ora, todos esses produtos já foram - ou ainda são - considerados pornografia.

$\mathrm{O}$ que fica claro nos dados sobre esse mercado é a enorme confusão das informações. Em primeiro lugar, muitos textos que pretendem informar sobre o tema designam tal comércio apenas como "pornografia", sem explicar se se refere a revistas, vídeos, internet ou à soma de tudo isso, como questionado acima. Da mesma forma, os números fornecidos por uma fonte comumente entram em conflito quando comparados com outra, a princípio tão legítima quanto a primeira. Muitas vezes, o que representa o valor mundial para um autor, é o valor regional para outro, durante o mesmo período. Além disso, existe outro dado extremamente importante: o próprio mercado genericamente considerado "pornográfico", visando se legitimar, busca fugir desse rótulo e, para ser melhor aceito socialmente, passa a se apresentar com termos como "mercado adulto", "mercado erótico" ou "entretenimento adulto".

Vejamos um exemplo tanto do desencontro de números quanto da dificuldade do próprio mercado em se auto-intitular: no sítio da revista Veja, em reportagem com data de 04 de outubro de 2009, na seção de economia, afirma-se que o "mercado erótico" nos Estados Unidos movimenta US\$12,46 bilhões por ano e, no Brasil, $\mathrm{R} \$ 1$ bilhão por ano - sem contar as produtoras de filmes pornôs e a parte de serviços, como motéis e casas noturnas. Esta última cifra é, segundo a revista, referente ao "comércio de produtos como próteses, vibradores e cosméticos" 3 , não deixando muito claro o que, além desses produtos, pertence ou não ao tal mercado. Os dados sobre nosso país são da Associação Brasileira de Empresas do Mercado Erótico - ABEME, uma entidade criada em 2002 visando à união de "companhias e profissionais dos diferentes segmentos do setor erótico: motéis, vídeos-locadora, revistas, vídeos, fabricantes de vestuário, brinquedos e sítios da

\footnotetext{
$3<$ http://veja.abril.com.br/noticia/economia/mercado-erotico-cresce-15-anobrasil>
} 
Jorge Leite Jr.

Internet entre outros" 4 com o objetivo de fortalecer o setor no Brasil. O termo pornografia não consta do nome da entidade, nem é usado nenhuma vez em seu sítio na internet como referência para seus representados ou produtos.

Já de acordo com Paula Aguiar - empresária e autora de um guia de negócios para quem quer abrir uma sex shop em nosso país - em seu livro, de 2009, segundo a ABEME, o tal "mercado erótico" no Brasil rende apenas 900 milhões de reais (Aguiar, 2009:23). Temos então uma diferença gigantesca entre os dados de uma mesma fonte e divulgados no mesmo período (não há, porém, indicação de que esses dados referem-se ao mesmo período contabilizado). Também nos dois volumes do guia publicado por essa autora, a palavra "pornografia" não é usada nenhuma vez.

Como podemos perceber, parece haver uma mistura de classificações. Para não ser julgado valorativamente (por sua carga histórica de desqualificação), o negócio dos produtos sexuais tenta se afastar da palavra pornografia e criar uma outra expressão, comumente associada ao termo erótico. Esse deslocamento semântico se deve à associação entre erotismo como uma forma legítima de representação da sexualidade, relacionada ao imaginário adulto, tanto para se pressupor uma concepção "madura" em relação à temática quanto, principalmente, para se distanciar e diferenciar do comércio ilegal da pornografia infantil. Mas afinal, segundo essa Associação (que pretende unir os profissionais da área de filmes, mas não contabiliza essas produções em seus dados), seus produtos podem ou não ser considerados como pornografia? E quem os considerará assim? O "mercado" em geral? Esse setor em particular? Alguma outra associação?

Em reportagem da Folha.com, de 07 de maio de 2011, na seção Mercado, a ABEME informa que os fabricantes do "mercado adulto" (termo do jornal) preferem "produtos com apelo mais sensual e menos erótico" (sem definir a diferença entre um $e$

$4<$ http://www.abeme.com.br/abeme-2/> 
outro) e que o setor continua movimentando o mesmo $\mathrm{R} \$ 1$ bilhão por ano no país, mas agora incluindo "filmes e serviços, como casas de suingue e profissionais do ramo". ${ }^{5}$ Ora, passados quase dois anos desde a informação anterior, contando agora com os lucros dos filmes e do grande setor de "serviços", a quantia movimentada continua a mesma, embora em seu sítio a ABEME afirme que o ano de 2010 registrou um "crescimento anual de 17\% em relação ao ano anterior". 6

Quanto aos números americanos, a cifra apresentada é quase a mesma da reportagem vista anteriormente: US\$ 12 bilhões. Apesar de não citar a fonte dessa informação, o texto afirma que a Free Speech Coalition - a maior associação norteamericana do setor e que tem como um de seus objetivos principais garantir legalmente a existência desta indústria (produção, produtos e consumo) - considera o valor elevado.. Seu sítio na internet não apresenta números - não oferecendo nenhuma informação "oficial" sobre o quanto esse mercado rende - e também não utiliza a palavra pornografia. O termo utilizado para seu negócio é "entretenimento adulto", como fica expresso em sua página: Adult Entertainment Trade Association. ${ }^{7}$

Podemos afirmar então que o termo pornografia se desenvolveu, durante o século XX, como 1) um sentido valorativo, comumente usado pelo discurso do senso comum, e 2) como uma classificação mercadológica - desenvolvida graças à sua legalização utilizada tanto pelo senso comum como pela mídia, embora a própria indústria considerada pornográfica não utilize esses termos para se autonomear, preferindo expressões como mercado erótico, mercado sensual ou indústria adulta, entre outras.

\footnotetext{
5 <http://www1.folha.uol.com.br/mercado/899262-produto-nacional-ganhaespaco-no-mercado-erotico.shtml>

6 O sítio da ABEME não apresenta os valores absolutos do total da renda anual do setor, apenas percentuais de crescimento.

7 <http://www.freespeechcoalition.com/index.php>
} 
Sendo assim, quando se fala de pornografia, de quê está se falando exatamente? Acredito que essa palavra e o mercado a ela associado se alimentam exatamente dessa indefinição. Ao se desenvolver como indústria e construir um mercado legal, a pornografia ramificou-se de forma rápida alcançando, atualmente, através dos milhares de páginas da internet consideradas pornôs, uma quantidade de divisões inimagináveis há algumas décadas. Por exemplo, apenas no campo audiovisual e através dos portais que servem de divulgação para outros sítios pornôs ${ }^{8}$, apresentando endereços promocionais com fotos ou vídeos gratuitos, encontramos páginas como a Elephant List $^{9}$, que possui 113 opções de subclassificações de pornografia, que vão de 18 years old à wild girls; ou a $X n x x^{10}$, que possui 118 opções que podem se subdividir, através de referências cruzadas, em quase mil outras!

Um exemplo desse labirinto classificatório onde se misturam sentidos valorativos, classificações comerciais, categorias científicas e conceituações nativas, é a produção pornográfica com pessoas que transitam entre os sexos e/ou gêneros, ajudando na permanência de um dos elementos imaginários mais fortes $e$ resistentes do universo pornô: a exotização do Outro, seja ele um brasileiro ou alguém conhecido genericamente como oriental (Piscitelli, 2002; Said, 1990; Weisz, 2007).

Ora, a pornografia nasce junto com o desenvolvimento da ciência sexual (Foucault, 1988) e com o colonialismo do século XIX. Esses três discursos, apesar de distintos em certos campos, foram profundamente interligados entre si. Conforme Larissa Pelúcio (2010:206),

\footnotetext{
8 Os sítios da internet pesquisados para este artigo são todos ocidentais voltados predominantemente para o público também ocidental, mesmo quando apresentam pessoas ou temas "orientais", sendo a quase totalidade deles escritos em língua inglesa.

$9<$ http://www.elephantlist.com/>

$10<$ http://www.xnxx.com/>
} 


\begin{abstract}
A exotização e erotização do "outro" tem sido formas de expressar, simbolicamente, nas relações cotidianas, processos de dominação econômica e cultural. $\mathrm{O}$ colonialismo parece ser um desses eventos que saturou de signos eróticos não só as terras "exóticas", mas também seus habitantes. Na tradição moderna ocidental o erótico guarda marcas históricas persistentes que dão sentido aos encontros sexuais contemporâneos.
\end{abstract}

Assim, a sexualização das raças colonizadas foi indissociável de uma racialização dos sexos, dos gêneros e das práticas sexuais (Pelúcio, 2010; Piscitelli, 2002; Rago, 2008; Young, 2005), sendo que a pornografia foi extremamente importante na difusão de um imaginário colonial que via seus nativos como inferiorizados, exotizados e sexualizados.

Como mostram Boëtsch e Ferrié (1998) ao analisarem cartões postais eróticos daquele período, algumas etnias chegam a ser literalmente inventadas nesses objetos que, por sua vez, influenciam na crença popular $e$, algumas vezes na crença científica, na existência de tais grupos. Esse é o caso das mouras, um grupo específico de mulheres da África do Norte que existia apenas nessas encenações fotográficas e apareciam em sua quase totalidade com os seios desnudos, adotando posições sensuais ou convidativas, insinuando tanto submissão sexual quanto um desejo ingênuo, mas intenso, pois apresentado como primitivo ou fragilmente civilizado.

Questões como a cor da pele ou os simbolismos religiosos que adornam essas mulheres têm uma importância menor nas imagens, segundo os autores:

esta oposição [entre as mouras com os seios de fora $e$ mulheres orientais cobertas por véus ou enclausuradas] provém do fato de que o cartão-postal tem como alvo a atração pelo exótico, que não reside na diferença religiosa, mas numa introdução ao erotismo da diferença (Boëtsch $e$ Ferrié, 1998:173). 
Jorge Leite Jr.

A quase totalidade das mouras eram modelos européias encenando um imaginário que refletia, antes de tudo, os desejos, esperanças e medos dos próprios colonizadores.

Esse imaginário que visa criar distinções hierarquizadas, mais do que compreender diferenças, também surge em sua versão midiática na segunda metade do XIX e se mantém, com nuances, até hoje. Conforme Weisz, apesar de Rabelais ${ }^{11}$ já haver utilizado o termo exótico no século XVI, ele aparece e se desenvolve apenas no século XIX: "O exótico definia um gosto pela arte e costumes de povos remotos. Uma sensação e uma experiência que prometiam aventuras inimagináveis" (Weisz, 2007:21).

A espetacularização do que é considerado estranho ou bizarro revela uma curiosidade que, muitas vezes, é usada principalmente para cavar abismos entre as culturas e demarcar as fronteiras entre um "nós civilizados" e os "outros bárbaros", sejam estes outros internos ou externos ao grupo que assim os julga. ${ }^{12} \mathrm{~A}$ pornografia, desde seu início, apresenta a versão sexualizada dessas pessoas e grupos "misteriosos", fascinantemente estigmatizados, envergonhadamente desejados, penosamente respeitados. Das delicadas mouras de seios nus africanas às exuberantes mulheres-frutas brasileiras, encontra-se toda uma tradição imagética na criação de um extraordinário sexual associado a um território forçosamente desconhecido.

Ainda conforme Pelúcio (2010; 2011), podemos encontrar esse imaginário do erotismo exotizado e do exótico erotizado funcionando atualmente nos sítios da internet de países como Espanha e Portugal (provavelmente também de grande parte da Europa), especializados em serviços sexuais prestados por travestis

\footnotetext{
${ }^{11}$ François Rabelais, hoje considerado um importante autor francês, mas que, por seus escritos repletos de humor debochado e descrição de atos sexuais, aparelhos genitais e funções excretoras, já foi classificado como perigoso e pornográfico.

12 Essa visão é explicitamente apresentada tanto no extinto jornal Notícias Populares (1963-2001), da cidade de São Paulo (Campos Jr. et alii), quanto na TV a cabo da National Geographic, através, por exemplo, do atual programa Tabu. http://www.natgeo.com.br/br/especiais/taboo/
} 
brasileiras. Segundo a autora, crenças e expectativas sobre a feminilidade brasileira, idealizada como naturalmente sensual, fogosa e sempre disponível sexualmente - pois vem de uma terra localizada em trópicos misteriosos com uma natureza luxuriante são negociadas nesses ambientes virtuais.

No caso das travestis, a extravagância lasciva chega a seus extremos pela própria condição sexualmente dúbia dessas figuras:

Os jogos eróticos que o exótico pode sugerir têm estreita relação com a própria corporalidade travesti. Seios e pênis, nádegas fartas e disponibilidade para o sexo anal, performance feminina $e$ a atividade sexual atribuída ao masculino, se encontram juntos nas travestis que atuam no mercado do sexo transnacional (Pelúcio, 2010:208).

É esse mesmo corpo das pessoas que transitam entre os sexos e os gêneros, que a pornografia irá espetacularizar, mantendo seu caráter de estranheza e maravilha através do embaralhamento de várias concepções: corporais, científicas, nativas e mercadológicas.

Conforme visto, a pornografia como um mercado cria constantemente uma série de subdivisões, em especial no espaço cibernético. Essa segmentação tem como objetivo o aumento desse ramo de negócio, utilizando-se de símbolos, valores $e$ conceitos locais como uma estratégia de expansão global (Mira, 1994), tanto como forma de reforço do mercado interno (através da valorização do que é considerado nativo), quanto da conquista de novos consumidores (através da sedução do estranho ou exótico). Nesse sentido, a pornografia - cujos produtos são feitos em um determinado país, mas que, intencionalmente ou não, através da rede mundial de computadores, podem alcançar consumidores em qualquer parte do planeta - é uma típica indústria transnacional.

No caso da pornografia envolvendo pessoas que transitam entre os sexos e/ou gêneros, temos uma situação exemplar de como as subclassificações pornôs são formadas através da 
Jorge Leite Jr.

apropriação de categorias conceituais não pertencentes ao mercado. Por exemplo, existem os milhares de sítios pornográficos que apresentam sexo com (ou entre) transexuais, travestis $e$ intersexos. Esses termos, antes de tudo, nomeiam pessoas que representam categorias criadas pelo discurso científico. Cada uma delas evoca uma especificidade conceitual. Na área da ciência, elas não podem ser usadas como sinônimos.

Optamos aqui por não citar literalmente as definições oficiais $^{13}$ de cada uma dessas categorias pois, apesar de compartilharem um conceito relativamente uniforme, elas mudam de acordo com o autor ou a instituição que as define. Essas categorias, como a pornografia, também têm uma série de subdivisões. No limite, a história nos mostra que nunca houve um consenso, dentro dos vários ramos da ciência, quanto a suas definições, usos e significados (Leite Júnior, 2008).

Para os fins deste artigo, acompanhando as definições médicas (e científicas), chamaremos de transexuais as pessoas que foram designadas em seu nascimento como pertencentes a um sexo, mas que se identificam com o gênero atribuído tradicionalmente ao sexo oposto. Grosseiramente, são pessoas que nasceram homens, mas se consideram mulheres ou viceversa. A grande maioria das transexuais altera o corpo para adquirir as formas do sexo/gênero desejado e muitas (mas nem todas) desejam a cirurgia de transgenitalização, pois sentem-se mal com o corpo "original". No universo pornô, o foco central são as transexuais vistas não como indivíduos em sofrimento, mas como seres hipersexualizados que, ao contrário de terem ojeriza para com o próprio corpo, utilizam-no como uma máquina de dar e

${ }^{13}$ Como as da Classificação Estatística Internacional de Doenças e Problemas Relacionados à Saúde, também conhecida como Código Internacional de Doenças (CID), organizado pela Organização Mundial de Saúde e as do Manual Diagnóstico e Estatístico de Transtornos Mentais (DSM), publicado pela Associação Psiquiátrica Americana. 
receber prazer. Na pornografia, elas também são reconhecidas pelo diminutivo TS. ${ }^{14}$

Travestis são pessoas que usam roupas e adereços do sexo "oposto" para adquirirem, principalmente, gratificação sexual ou aliviarem um período de tensão psíquica, segundo o Manual Diagnóstico e Estatístico de Transtornos Mentais (DSM) editado pela Associação Psiquiátrica Americana (a instituição que rege a psiquiatria ocidental) e a Classificação Estatística Internacional de Doenças e Problemas Relacionados à Saúde (CID), publicada pela Organização Mundial de Saúde.

No Brasil, existe uma questão terminológica extremamente interessante: o que é comumente conhecido e reconhecido aqui em nosso país, pela cultura popular ou de massas, como uma pessoa travesti, ou seja, aquela que adota o gênero feminino, sofre intervenções hormonais e cirúrgicas para feminilizar seu corpo como, por exemplo, colocando próteses de silicone nos seios adota as vestimentas, adereços, comportamentos e nomes considerados tipicamente de mulheres, vivendo 24 horas por dia nessa condição e não desejando a cirurgia de transgenitalização, é classificada nestes manuais - DSM e CID - como uma pessoa com certo grau de transexualidade. Ou seja, o que chamamos em nosso país de travesti, é chamada nestes livros médicos de transexual.

Assim, como Don Kulick (2008) já havia notado, travesti em nosso país é uma classificação local, não se referindo ao conceito clínico de travestismo. O importante a ressaltar é que transexual e travesti são categorias científicas, referentes a patologias psíquicas, ao mesmo tempo em que travesti também é uma classificação nativa brasileira vinda da cultura popular e midiática. No universo da pornografia cibernética, a palavra travesti parece se referir a ambas referências, com uma tendência a aumentar a associação dessa subdivisão do mercado pornô com a concepção regional das travestis brasileiras, graças ao sucesso que elas alcançam hoje

$14<$ http://www.tsporn.net/ > 
Jorge Leite Jr.

na Europa (Pelúcio, 2010; 2011) e na internet como um todo, quando o assunto é esse tipo de material. ${ }^{15}$

Outro dado extremamente importante é que, por serem criadas pelo discurso da ciência, as categorias científicas carregam o pressuposto de sua universalidade e atemporalidade, alcançadas através da verificação empírica e da reflexão proporcionada pela capacidade racional humana. Ou seja, elas devem ser válidas para poder classificar qualquer pessoa do planeta, em qualquer período histórico, desde que se enquadre nas descrições aceitas pela comunidade científica - descrições que, no entanto, não são uniformes e mudam histórica e mesmo regionalmente. ${ }^{16}$ Baseados nesses pressupostos de categorias "universais" é que estudiosos da transexualidade, comumente das ciências da psique, procuram por "transexuais" tanto na Idade Média europeia quanto no Oriente contemporâneo (Ceccarelli, 2008; Farina, 1982; Paiva e Vieira, 2009; Pinto e Bruns, 2003; Ramsy, 1998; Saadeh, 2004; Verde e Graziottin, 1997).

Além disso, na pornografia existe a figura dos hermafroditas e andróginos. Ora, estas são categorias extremamente curiosas, pois podem se referir tanto ao discurso científico (ainda há linhas da medicina e da psicologia que trabalham com essas classificações), quanto ao discurso mítico-religioso (que considera tais pessoas em relação a um universo mágico e sagrado, muitas vezes mais próximas dos seres divinos que das patologias orgânicas). Dentro da medicina, ainda se mantém a classificação de pseudo-hermafroditas ou hermafroditas verdadeiros, sendo estas uma versão antiga, mas ainda em uso, do que se chama atualmente de intersexos, sujeitos com "distúrbio do desenvolvimento sexual" ou com "anomalias da diferenciação

$15<$ http://www.travestisbr.com.br/>

${ }^{16}$ Como exemplo, podemos citar a França que, em 2009, através de seu Ministério da Saúde, deixou de considerar a transexualidade um transtorno mental, embora ela ainda seja considerada desta forma tanto pela Organização Mundial da Saúde quanto pela Associação Psiquiátrica Americana (que a nomeia como "transtorno de identidade de gênero"). 
sexual" (Damiani e Guerra-Jr., 2007). Essas expressões são usadas para designar pessoas com algum tipo de ambiguidade genital e/ou sexual, no qual o foco está no corpo do indivíduo. Já na psicologia junguiana, por exemplo, algumas autoras trabalham com o conceito de androginia (Singer, 1990), cujo foco da união entre homem/mulher, masculino/feminino é a mente ou, sociologicamente falando, o gênero do sujeito. No campo da pornografia, a palavra intersexo é raramente usada e não possui a especificidade de um corpo contendo os dois genitais ou algum "distúrbio" do tipo, sendo empregada como mais um sinônimo de transexual ou travesti.

Da mesma forma, também encontramos nas produções pornôs concepções classificatórias nativas ou regionais, tanto ocidentais quanto orientais. Existem literalmente milhares de sítios na internet apresentando filmes e fotografias com travestis ${ }^{17}$, shemales (ou she-males), trannys e CDs.

Shemale é um termo popular norte-americano que, no século XIX, se referia pejorativamente a mulheres vistas como masculinizadas e, gradualmente, foi sendo apropriado pela indústria pornô para designar as pessoas biologicamente homens que fazem alterações em seus corpos para se adequarem ao gênero feminino. Esse termo é intimamente associado ao mercado do sexo nos Estados Unidos, especialmente à pornografia. ${ }^{18}$

Grosso modo, a mesma coisa pode ser dita quanto a tranny, com menos referência direta ao trabalho sexual na cultura popular americana, mas com o mesmo foco na sexualidade intensa dentro do mercado pornô. ${ }^{19}$ Uma coisa curiosa parece estar ocorrendo com esse termo na pornografia virtual: ele conquista cada vez mais espaço nesse ambiente. Um exemplo é que, em 2008, a Grooby

\footnotetext{
${ }^{17}$ No sentido brasileiro do termo, como já visto.

$18<$ http://www.shemalepornclips.com/>

$19<$ http://www.free-trannyporn.com/ > ou < http://www.rincontranny.com/> conforme analisado por Larissa Pelúcio (2011).
} 
Jorge Leite Jr.

Productions ${ }^{20}$, uma produtora estadunidense especializada nessa linha de filmes - apoiada por uma série de outras produtoras do ramo - criou o Tranny Awards ${ }^{21}$, uma premiação especialmente voltada para essa subdivisão de mercado, mostrando sua importância mundialmente crescente. ${ }^{22}$

$C D$ é um exemplo curioso. Esse termo é a diminuição de crossdresser, uma palavra criada também pela ciência (no fim do século XIX) e que rapidamente adquiriu vida própria na cultura popular e de massas americana. Frequentemente, é usado para se referir, grosso modo, a pessoa que gosta de se vestir com roupas do sexo dito oposto ao seu sexo biológico, independente de sua orientação sexual e que, comumente, não realiza mudanças definitivas no corpo como o implante de próteses para os seios eventualmente fazendo uso de hormônios - e se contentando, na maioria das vezes, com uma "montagem" restrita a algumas horas por dia/semana ou a períodos mais significativos da vida. Dentro do discurso científico, as $C D^{\prime}$ s estão mais próximas da categoria clínica de travestis. ${ }^{23} \mathrm{Na}$ visão médica não existe obrigatoriamente a associação com a excitação sexual em fazer a troca de roupas, embora na pornografia ela seja o elemento principal. ${ }^{24}$

Dentro do que é genericamente chamado de "Oriente", um conceito guarda-chuva para englobar os territórios, povos $e$ culturas "a leste" da Europa, que não compartilham completamente dos mesmos pressupostos, valores e ideais da "modernidade ocidental" (Said, 1990), também existem classificações regionais para englobar as pessoas que transitam entre os sexos/gêneros e que são apropriadas pela pornografia. "Futanari", "kathoey" e "hijra" são alguns dos termos que

\footnotetext{
$20<$ http://www.grooby.com/>

$21<$ http://www.trannyawards.com/index.php>

${ }^{22}$ Como, por exemplo, o sítio Third World Shemales, um dos apoiadores dessa premiação - <http://www.thirdworldshemales.com/>

$23<$ http://www.transvestite-porn.com/>

$24<$ http://thecrossdressers.com/>; < http://www.crossdressporn.com/>
} 
aparecem em sítios que visam espetacularizar sexualmente as "pessoas orientais".

Futanari é um nome japonês para designar, no vasto $e$ complexo universo dos animes e mangás eróticos daquele país, um tipo de personagem, quase sempre feminina, que possui os dois genitais (o masculino e o feminino), ou uma mulher que possui pênis e testículos. ${ }^{25}$ Apesar do termo se referir quase que exclusivamente ao universo dos desenhos animados e quadrinhos, existem já algumas produções pornôs que mostram garotas, quase que exclusivamente ocidentais, possuindo e utilizando pênis artificiais gigantescos, como se fizessem parte de seus corpos. ${ }^{26}$ Já para as pessoas reais, além dos termos americanos, também é comum na pornografia japonesa o uso da expressão (também americana) new-half. ${ }^{27}$

Kathoey é a nomeação para as pessoas que transitam entre os sexos/gêneros, quase que exclusivamente do masculino/homem para o feminino/mulher, na Tailândia; na Índia, em Bangladesh e no Paquistão, o termo é hijra. Ambas possuem funções tradicionais tanto no campo artístico (especialmente na Tailândia) quanto no religioso, sendo as kathoeys associadas a determinadas formas regionais de espiritualidade budista $e$ as hijras a manifestações da espiritualidade tanto hindus quanto muçulmanas (Champassak, 2003).

Não entrarei na complexidade dos particularismos culturais de cada classificação, seus significados e suas especificidades (Champassak, 2003; Totman, 2003). Gostaria apenas de apontar que ambas possuem uma diferença fundamental em relação às categorias ocidentais: enquanto transexuais, travestis e intersexuais são categorias referidas à ciência e tais pessoas são encaradas como doentes (do corpo ou da psique), kathoeys e hijras estão relacionadas ao universo religioso, sendo vistas como possuidoras

\footnotetext{
$25<$ http://futanari-porn.com/>

${ }^{26}<$ http://www.futanaria.com/ $>$

${ }^{27}<$ http://www.shemale-japan.com/>
} 
Jorge Leite Jr.

de um determinado tipo de sacralidade - generosa mas, ao mesmo tempo, perigosa. Não quero dizer com isso que no "Oriente" não exista discriminação ou que é melhor ou mais fácil ser uma hijra do que uma transexual. Gostaria apenas de ressaltar as diferentes origens conceituais dessas classificações que, no limite, podem levar a distintas maneiras de lidar (tanto na aceitação quanto na discriminação) com essas pessoas.

No campo pornô, se o termo hijra é pouco encontrado (provavelmente por ser referente a religiões que tradicionalmente não aceitam a pornografia), kathoey não é uma palavra difícil de estar relacionada a esse mercado. ${ }^{28} \mathrm{~A}$ Tailândia é considerada um dos maiores centros de turismo erótico do mundo e as kathoeys são internacionalmente famosas por sua feminilidade e seus serviços sexuais. O termo importado ladyboy (Totman, 2003:10), extremamente popular naquele país, é também, na pornografia, a palavra-chave principal usada para se referir a essas pessoas não apenas tailandesas, mas orientais em geral. ${ }^{29}$

Sob esse guarda-chuva terminológico de ladyboy, o mercado pornô agrupa para o (também genérico) "Ocidente" uma série de variações nativas orientais sobre as pessoas que transitam de um sexo/gênero para outro, vendendo a imagem de um Oriente carregado de mistérios e segredos sexuais, extravagantemente exotizado e hiperbolicamente erotizado, onde existem mulheres que, além de lânguidas, obedientes e sempre disponíveis sexualmente, possuem um membro viril. Mesmo a clara diferença entre os seios exuberantes das shemales, trannys, travestis ou transexuais - usados como um importante símbolo da feminilidade ocidental - $e$ os pequenos $e$ discretos seios das ladyboys, parece reforçar esse imaginário de delicadeza $e$ submissão da feminilidade oriental.

Essa é uma ideia persistente no imaginário colonial (e pomográfico): a submissão, docilidade, conformismo e disponibilidade -

\footnotetext{
$28<$ http://www.kathoeyporn.com/>

$29<$ http://ladyboyporn.net/>; <http://asiants.com/>
} 
sempre permeada de sensualidade - do colonizado, do Outro. Por isso, essas características podem ser atribuídas tanto a japonesas, mouras ou brasileiras. Conforme Adriana Piscitelli, analisando obras literárias sobre encontros turístico-sexuais entre norteamericanos e europeus com pessoas de países historicamente colonizados e cultural e economicamente subordinados,

a ideia de exotismo é construída através de procedimentos nos quais a alteridade é delineada mediante distinções inseridas em nítidas relações de desigualdade - no sentido de distribuições diferenciadas de poder (Piscitelli 2002:218).

Contudo, não quero afirmar que as pessoas e grupos exotizados não possuam agência ou não saibam tirar proveitos de sua situação. Talvez o exotismo seja, mais do que uma imposição, uma negociação forçada, desenvolvida dentro de uma relação desigual.

Como exemplo desse cruzamento de referenciais coloniais, sexuais e raciais exotizados e espetacularizados na pornografia, utilizando múltiplas classificações, podemos citar os sítios na internet de Long Mint $^{30}$, uma performer/atriz pornô tailandesa que, provavelmente em sua terra é reconhecida como uma kathoey, mas que apresenta-se como uma ladyboy - como já vimos, um termo em inglês usado genericamente para nomear as pessoas vistas como "orientais" que transitam entre os gêneros (especialmente do masculino para o feminino). Em seu sítio oficial e em várias outras páginas promocionais dessa atriz, uma série de clichês relacionados a um imaginário ocidental em relação ao "Oriente" - tanto sobre sexualidade, quanto sobre etnias - é acionada de maneira explicitamente exotizante, buscando reforçar o caráter de fascinação, novidade e bizarrice da modelo. A começar pela questão do pênis.

$30<$ http://www.longmint.com/>; <http://www.pichunter.com/sítios/long_mint >; $<$ http://www.longmintshemale.com/ >; $\quad<$ http://www.longmint.net/?ai=1 $>$; $<$ http://www.ladyboylongmint.com/ >; < http://mintladyboy.com/hard/> 
Long Mint anuncia que possui um pênis de 22,5 cm (ou 9"). Aqui já se confundem dois importantes estereótipos corporais $e$ sexuais criados pelo Ocidente e quase que excludentes um do outro, nesse caso específico: os de que os negros possuem pênis maiores e os orientais possuem pênis menores que os chamados caucasianos.

David Friedman (2002) mostra como, durante o processo de racialização dos povos colonizados e escravizados, os estudos para a tentativa de criação de um padrão sobre tamanho do pênis do homem branco europeu foram fundamentais para classificar outros povos como bestiais e perigosos (por possuírem um pênis visto como muito grande) ou submissos e obedientes (de acordo com seus pênis compreendidos como pequenos). Conforme esse autor

diferenças de tamanho receberam grande peso por parte
desses teóricos, geralmente no modo 'o maior é o melhor' -
com uma exceção evidente: o cérebro maior dos
caucasoides provava a sua superioridade intelectual e seu
status civilizado, mas o pênis maior dos negros provava sua
inferioridade intelectual e sua selvageria inata (Friedman,
2002:98).

Abreu (1996) e Christy (2001) já analisaram a importância que o pênis possui para a pornografia em geral, especialmente a hetero e a homossexual masculina. Conforme esta segunda autora, a partir dos anos 90 do século $\mathrm{XX}$, "os pênis tiveram que ficar maiores, as atrizes mais submissas e a ação mais selvagem" (Dian Hanson in Christy e Quinn, 2001:517). Linda Williams (2004) também analisa a importância do tamanho do pênis, em especial o do homem negro, no imaginário e na pornografia estadunidense, mostrando como muitos filmes ajudaram a reinscrever a questão da sexualidade negra no país não apenas como perigosa, mas também como bela e estimulante, ajudando a 
torná-la assim legitimamente desejável no espaço social, e não mais apenas na fantasia privada.

Ora, os sítios de divulgação de Long Mint parecem saber estimular e jogar com esses estereótipos racializantes. Em algumas imagens, sua pele aparece escura ${ }^{31}$, em outras sua cor é bem clara. ${ }^{32}$ As imagens de seu rosto, apoiadas em maquiagem $e$ figurino, ora reforçam traços orientais ${ }^{33}$, ora tentam diminuí-los. ${ }^{34}$ E seu longo pênis aparece como o foco central e seu grande diferencial. Exaltando suas capacidades únicas, bizarras (no sentido de estranhas, curiosas, diferentes) e exóticas, essa atriz é mostrada fazendo sexo oral em si mesma ${ }^{35}$ e penetrando seu pênis em seu próprio ânus ${ }^{36}$, promovendo - com essa mistura de prática sexual e masturbação, atividade e passividade em si mesma - um sensacional ingrediente de novidade e exclusividade desse produto pornográfico.

Outra especialidade de Long Mint parece ser a representação visual do imaginário dito fetichista ocidental. Todos os estereótipos ocidentais associados a roupas, profissões $e$ posições de poder do Ocidente estão presentes em seus ensaios, tais como a enfermeira, a policial, a dominatrix, a escrava, a oriental, a militar, a rebelde, a colegial, a dona de casa, a fumante (algo cada vez mais obsceno no imaginário ocidental), a mulher de cabelos loiros, morenos ou ruivos (longos, lisos, enrolados ou curtos), entre outros. ${ }^{37}$ Em um dos ensaios, Mint encarna Marylin

\footnotetext{
$31<$ http://www.ladyboylongmint.com/page/2/>;

< http://www.longmint.net/?ai=1 > ; < http://mintladyboy.com/hard/page/4/>

$32<\mathrm{http}: / /$ mintladyboy.com/hard/>; <http://www.longmintshemale.com/>

$33<$ http://www.ladyboylongmint.com/page/2/>;

<http://fhg.lb-69.com/lb-69/002_Mint_White_Video/index.php?id=1494431>

$34<$ http://www.ladyboylongmint.com/>

$35<$ http://www.ladyboylongmint.com/ >

$36<$ http://mintladyboy.com/hard/>

$37<$ http://www.longmintshemale.com/>;

$<$ http://www.ladyboylongmint.com/page/2/>
} 
Jorge Leite Jr.

Monroe, uma das mais representativas figuras femininas e eróticas da cultura midiática ocidental, agora possuindo um longo $e$ chamativo pênis. ${ }^{38}$

E entre as fantasias (vestuário e desejo) de esportistas apresentadas por por Long Mint, uma revela-se extremamente adequada para esta reflexão: a atriz vestida com um biquíni verde e amarelo contendo na parte que cobre o seio direito, o brasão da seleção brasileira de futebol, e cobrindo o esquerdo, a bandeira do Brasil. ${ }^{39}$ Aqui, duas nacionalidades distintas, mas próximas no imaginário exótico, cruzam-se para reforçar a potência da pornografia com pessoas que transitam entre os gêneros.

Ora, Tailândia e Brasil são reconhecidos internacionalmente como paraísos sexuais, onde a disponibilidade das mulheres (e do corpo feminino) é fácil e a disposição para o sexo é quase infinita. Além disso, os dois países são vistos como exportadores de travestis (Pelúcio, 2011:452) e ladyboys para o mercado transnacional de sexo - incluindo o mercado pornô -, sendo essas pessoas consideradas também como as maiores modelos (inter)nacionalizadas de beleza e feminilidade nesse campo. Ao vestir uma roupa fazendo referência direta ao futebol brasileiro, conhecido mundialmente como um dos melhores do mundo, Long Mint não apenas brinca com a virilidade de um esporte tradicionalmente visto como masculino, mas, indiretamente, ela evoca como símbolo do Brasil não o reconhecido e legitimado esporte nacional, mas as exóticas e subalternizadas travestis.

Jogando com raça, nacionalidade, prática sexual, gênero $e$ uma série de outros marcadores sociais de diferenças, Long Mint parece ir além da simples questão "é homem ou mulher?" fundamental para a estigmatização das pessoas que transitam entre os gêneros -, evocando uma série de outras como "tem pele escura ou clara? É negra, ou mestiça? Oriental ou ocidental? Passiva ou ativa? Kathoey, ladyboy ou shemale?" Essas perguntas,

\footnotetext{
$38<$ http://www.ladyboylongmint.com/page/2/>

${ }^{39}$ Figura 1, disponível em: < http://mintladyboy.com/hard/>
} 
mesmo exotizando, revelam a fragilidade das classificações empregadas e sua dinâmica nas relações de poder, tão bem exploradas no mercado pornô. O Brasil possui suas travestis e a Tailândia suas kathoeis, mas, no vasto território da pornografia, todas podem ser classificadas como ladyboys ou shemales.

Percebemos então como a pornografia, como uma classificação mercadológica, utiliza-se da exotização de categorias científicas e concepções raciais e nativas, além de referenciais raciais e étnicos, para ampliar seu comércio.. Nesse sentido, termos como transexual (TS), travesti (TV), intersexo, andrógino, hermafrodita, shemale, tranny, crossdresser, futanari, new-half, hijra, kathoey e ladyboy ${ }^{40}$ (entre outros constantemente criados ou apropriados, como t-girl) são usados genericamente como sinônimos não apenas de pessoas que transitam entre os sexos/gêneros, mas de exotismos esteticamente marcados e sensacionalmente sexualizados. Afinal, a própria noção de pornografia é uma forma de categorização ocidental voltada para um mercado global, representando um dos principais discursos contemporâneos de uma sexualidade econômico-midiática transnacional.

Como as pessoas espetacularizadas por essas produções, às vezes vistas como homens e mulheres ao mesmo tempo, outras como nem homens nem mulheres, a pornografia se alimenta dessas imprecisões conceituais: nem unicamente uma categoria pseudo-científica, nem somente um termo valorativo, nem totalmente uma classificação mercadológica. $O$ rigor das definições precisas engessa e contrasta com a multiplicidade de sentidos que é justamente a matéria-prima das suas inúmeras e fluidas subdivisões pornográficas.

Da mesma forma, muito do exotismo sexualmente racializado não é encontro ou troca de desejos e fantasias

\footnotetext{
${ }^{40}$ Onde cada um desses termos se refere a uma maneira específica e distinta de compreender essas pessoas, seja através de referenciais científicos, populares, religiosos ou midiáticos.
} 
Jorge Leite Jr.

socialmente estigmatizadas (Williams, 2004), mas uma maneira estimulante e reificada de manter o Outro como um desigual, tentando desesperadamente evitar qualquer mudança substantiva nas já pressupostas relações de poder. Nesse cada vez mais saturado e competitivo mercado mundializado da pornografia, a difusa fronteira entre a universalidade científica $e$ a regionalidade nativa mostra-se como um vasto território a ser colonizado pela lógica da indústria pornô. Como afirma a página da internet apropriadamente intitulada Exotic Porn Site: "pornô de outras partes do mundo e tudo mais de exótico". ${ }^{41}$

\section{Referências bibliográficas}

ABREU, Nuno César. O Olhar Pornô. Campinas, Mercado das Letras, 1996.

AguiAR, Paula. SexShop.com - Guia de negócios. São Paulo, Edição do autor, volume 2, 2010.

. SexShop - Guia de negócios. São Paulo, Edição do autor, volume 1, 2009.

BOËTSCH, Gilles e FERRIÉ, Jean-Noël. A Moura de Seios Nus: O Imaginário Erótico Colonial no Cartão-Postal. In: SAMAIN, Etienne. (org.) O Fotográfico. São Paulo, Hucitec/ CNPQ, 1998, pp.169-176

BOURDIEU, Pierre. A economia das trocas lingüísticas - $O$ que falar quer dizer. São Paulo, Edusp, 1998.

. La distinción. Madrid, Taurus, 1988.

. A economia das trocas lingüísticas. In: ORTIZ, Renato. (org.)

Grandes Cientistas Sociais - Bourdieu. São Paulo, Ática, 1983.

CAMPOS JR. Celso de, et alii. Nada mais que a verdade. A extraordinária história do jomal NotíciasPopulares. São Paulo, Carrenho Editorial, 2002.

Ceccarelli, Paulo Roberto. Transexualismo. São Paulo, Casa do psicólogo, 2008

$41<$ http://www.exoticpornsite.com/> 
Labirintos conceituais científicos, nativos e mercadológicos

CHAmpassaK, Tiane Doan Na. Le sexe des anges. Paris, Éditions de La Martinière, 2003

CHRISTY, Kim e QUINN, John, The Christy Report - Exploring the outer edges of the sexual experience. New York, Taschen, 2001.

DAMIANI, Durval e GUERRA-JÚNIOR, Gil. As novas definições e classificações dos estados intersexuais: o que o Consenso de Chicago contribui para o estado da arte? Arq. Bras. Endocrinol. Metab., São Paulo, vol. 51, $\mathrm{n}^{\circ}$ 6, agosto 2007, pp.1013-1017. Disponível em: $<$ http://www.scielo.br/scielo.php?script=sci arttext\&pid=S000427302007000600018\&lng=en\&nrm =iso > . Acesso em: 05/03/2012.

DíAz-BEníTEZ, María Elvira. Nas redes do sexo: os bastidores do pornô brasileiro. Rio de Janeiro, Zahar, 2010.

El FAR, Alessandra. Páginas de sensação. São Paulo, Companhia das Letras, 2004.

FARINA, Roberto. Transexualismo - Do homem à mulher normal através dos estados de intersexualidade e das parafilias. São Paulo, Novalunar, 1982.

FoucAult, Michel. História da Sexualidade I - A Vontade de Saber. Rio de Janeiro, Graal, 1988.

FREIRE, João. Prazeres Desprezados: a Pornografia, seus Consumidores e seus Detratores. LUGAR Comum - Estudos de Mídia, Cultura e Democracia, $n^{\circ}$ 12, Rio de Janeiro, Núcleo de Estudos e Projetos em Comunicação da Escola de Comunicação - NEPCOM/UFRJ, 2001, pp.65-85.

FRIEDMAN, David M. Uma mente própria. A história cultural do pênis. Rio de Janeiro, Objetiva, 2002.

GRANT, Michel e Mulas, Antonia. Eros en Pompeya - El gabinete secreto Del Museo deNápoles. Barcelo, Ediciones Daimon, Manuel Tamayo, 1976.

GREGORI, Maria Filomena. Prazer e perigo. Notas sobre feminismo, sexshops e S/M. In: PISCITELl, Adriana, GREGORI, Maria Filomena e CARRARA, Sérgio. (orgs.) Sexualidade e saberes: convenções $e$ fronteiras. Rio de Janeiro, Garamond, 2004. 
Jorge Leite Jr.

HunT, Lynn. Obscenidade e as Origens da Modernidade (1500-1800). In: HunT, Lynn. (org.) A Invenção da Pornografia. São Paulo, Hedra, 1999, pp.09-46

JACOB, Margaret C. O Mundo Materialista da Pornografia. In: Hunt, Lynn. (org.) A Invenção da Pornografia. São Paulo, Hedra, 1999, pp.169-215

KuLICK, Don. Travesti. Rio de Janeiro, Editora Fiocruz, 2008.

LEITE JÚNIOR, Jorge. "Nossos Corpos Também Mudam": sexo, gênero e a invenção das categorias "travesti" $e$ "transexual" no discurso médico científico. Tese de Doutorado em Ciências Sociais, Pontifícia Universidade Católica, São Paulo, 2008.

MELlino, Miguel. La crítica poscolonial. Buenos Aires, Paidós, 2008.

MIRA, Maria Celeste. O global e o local: mídia, identidades e usos da cultura. Revista Margem no 3, São Paulo, - Faculdade de Ciências Sociais da PUC-SP/ , Educ, 1994, pp.131-149.

MoraEs, Eliane Robert. O Efeito Obsceno. Cadernos Pagu (20), Campinas-SP, Núcleo de Estudos de Gênero-Pagu/Unicamp, 2003, pp.121-130. Disponível em: <http:/www.scielo.br/pdf/cpa/n20/n20a04.pdf> - Acesso em:30/02/2012.

PAIVA, Luiz Airton Saavedra de e VIEIRA, Tereza Rodrigues. A transexualidade no passado e o caso Roberta Close. In: VIEIRA, Tereza Rodrigues e PAIVA, Luiz Airton Saavedra de. (orgs.) Identidade sexual e transexualidade. São Paulo, Roca, 2009, pp.1-11.

PELÚCIO, Larissa. Deseos, brasilidades y secretos - El negocio del sexo en la relación entre clientes españoles y travestis brasileñas. In: PAVEZ, Jorge e KRAUSHAAR, Lilith. (eds.) Capitalismo y pornología. San Pedro de Atacama, QLLQA/Universidad Católica Del Norte, 2011, pp.437-461

. Exótica, erótica e travesti - nacionalidade e corporalidade no jogo das identidades no mercado transnacional do sexo. In: CASTRO, Ana Lúcia de. (org.) Cultura contemporânea, identidades $e$ sociabilidades: olhares sobre corpo, mídia e novas tecnologias. São Paulo, Cultura Acadêmica/ UNESP, 2010, pp.197-213. 
Labirintos conceituais científicos, nativos e mercadológicos

PISCITELli, Adriana. Exotismo e autenticidade, relatos de viajantes à procura de sexo. Cadernos Pagu (19), Campinas-SP, Núcleo de Estudos de Gênero - Pagu/Unicamp, 2002, pp.195-231. Disponível em: <http://www.scielo.br/pdf/cpa/n19/n19a09.pdf>-Acesso em: 27/04/2012.

PINTO, Maria Jaqueline Coelho e BRuns, Maria Alves de Toledo. Vivência transexual - o corpo desvela seu drama. Campinas, Átomo, 2003.

RAGO, Margareth. O corpo exótico, espetáculo da diferença. Labrys Estudos Feministas, janeiro/junho, 2008. Disponível em: $<$ http://www.tanianavarroswain.com.br/labrys/labrys13/perspectivas/ marga.htm $>$

RAMSEY, Gerald. Transexuais - perguntas e respostas. São Paulo, Summus, 1998.

SAADEH, Alexandre. Transtornos de identidade sexual: um estudo psicopatológico de transexualismo masculino e feminino. Tese de doutorado em Ciências, Faculdade de Medicina, USP, São Paulo, $2004 . \quad$ Disponível em: $<$ http://www.teses.usp.br/teses/disponiveis/5/5142/tde-09082005115642/pt-br.php> - Acesso em: 22/02/2012.

SAID, Edward W. Orientalismo - o Oriente como invenção do Ocidente. São Paulo, Companhia das Letras, 1990.

SINGER, June. Androginia - rumo a uma nova teoria da sexualidade. São Paulo, Cultrix, 1990.

TOTMAN, Richard. The third sex - Kathoei: Thailand's ladyboys. London, Souvenir Press, 2003.

VERDE, Jole Baldaro e GRAzIOTTIN, Alessandra. Transexualismo o enigma da identidade. São Paulo, Paulus, 1997.

WeISZ, Gabriel. Tinta del exotismo. México, Fondo de cultura econômica, 2007.

WILLIAMS, Linda. Skin flicks on the racial border: pornography, exploitation, and interracial lust. In: WiLliams, Linda. (ed.) Porn studies. London, Duke University Press, 2004, pp.271- 308.

Young, Robert J. C. Desejo colonial. São Paulo, Perspectiva, 2005. 